\title{
Outcome of minimally-invasive versus open pancreatectomies for solid pseudopapillary neoplasms of the pancreas: A 2:1 matched case-control study
}

\author{
Hwee Leong Tan, Ek Khoon Tan, Jin Yao Teo, Juinn Huar Kam, Ser Yee Lee, \\ Peng Chung Cheow, Prema Raj Jeyaraj, Pierce K. Chow, Alexander Y. Chung, \\ London L. Ooi, Chung Yip Chan, and Brian K. P. Goh
}

\author{
Department of Hepatopancreatobiliary and Transplant Surgery, Singapore General Hospital, Singapore
}

\begin{abstract}
Backgrounds/Aims: Solid pseudopapillary neoplasm (SPPN) is typically seen in young healthy females who would likely benefit from minimally-invasive pancreatectomy (MIP). A few comparative studies have suggested that MIP is associated with favorable outcomes when compared to the open approach for SPPN. This study aims to mitigate potential selection bias by performing a matched case-control study comparing MIP vs open pancreatectomy (OP) for SPPN. Methods: We performed a single-institution retrospective electronic chart review of all patients who underwent surgery for pathologically confirmed SPPN between 2000 and 2017. A 2:1 matched comparison using age, gender, tumor size and the type of pancreatectomy was performed between OP and MIP. Results: A total of 40 patients with a median age of 40.3 years (range 16.5-64.4) and female sex predominance $(n=34,85.0 \%)$ underwent surgery during the study period. Nine patients underwent MIP. Matched comparison between 18 OP and 9 MIP demonstrated that MIP was associated with a longer median operating time (305 vs $180 \mathrm{~min}, p=0.046)$ and shorter median postoperative stay (6 vs 9 days, $p=0.015)$. There were no significant differences in intraoperative blood loss, blood transfusion requirements, postoperative morbidity (including postoperative pancreatic fistula) and mortality, resection margins, lymph node yield and long-term survival. Conclusions: MIP is a safe and viable option in the management of SPPN with the benefit of a shorter postoperative length of stay at the expense of a longer operation time. There was no significant difference in oncologic outcomes between both groups of patients. (Ann Hepatobiliary Pancreat Surg 2019;23:252-257)
\end{abstract}

Key Words: Laparoscopic pancreatectomy; Minimally-invasive pancreatectomy; Robotic pancreatectomy; Solid pseudopapillary neoplasm

\section{INTRODUCTION}

Solid pseudopapillary neoplasms (SPPN) are rare primary neoplasms of the pancreas comprising $1-2 \%$ of exocrine pancreatic tumors. ${ }^{1-3}$ These were previously referred to using a variety of descriptive and eponymous names, before official nomenclature was proposed by the World Health Organization in 1996 and its classification as a borderline malignant tumor of the exocrine pancreas. ${ }^{4-7}$ Over the past two decades, there has been an increasing frequency of cases of these tumors diagnosed and reported in the literature partly due to the widespread use of cross sectional imaging and better knowledge of the condition. ${ }^{7.8}$
SPPN have been well characterized as a tumor predominantly seen in young females in the second and third decades of life. ${ }^{1-3,7-9}$ Surgical resection is routinely indicated due to its frequency of symptomatic presentations and substantial risk of metastatic progression described in up to $15 \%$ of cases. $^{7,9-12}$

Minimally invasive surgery (MIS) has gained increasing widespread acceptance for pancreatectomies, with several meta-analyses reporting improved perioperative pain control, decrease postoperative morbidity rates and shorter postoperative length of stay associated with minimally-invasive pancreatectomies (MIP). ${ }^{13-18}$ These attendant advantages, alongside improved scar cosmesis and decreased long-

Received: February 7, 2019; Revised: March 25, 2019; Accepted: March 29, 2019

Comesponding author: Brian K. P. Goh

Department of Hepatopancreatobiliary and Transplant Surgery, Singapore General Hospital, 20 College Road, 169856 [546149], Singapore Tel: +65-98156448, Fax: +65-98156448, E-mail: Bsgkp@hotmail.com

Copyright (C) 2019 by The Korean Association of Hepato-Biliary-Pancreatic Surgery

This is an Open Access article distributed under the terms of the Creative Commons Attribution Non-Commercial License (http://creativecommons.org/ licenses/by-nc/4.0) which permits unrestricted non-commercial use, distribution, and reproduction in any medium, provided the original work is properly cited. Annals of Hepato-Biliary-Pancreatic Surgery • pISSN: 2508-5778 - eISSN: 2508-5859 
term wound complications, would potentially prove especially invaluable in the typical SPPN patient which usually comprises young healthy females with a long-life expectancy. ${ }^{1-3,7-9}$

Presently, there have only been a limited number of studies with small sample sizes reporting on the outcomes of MIP for SPPN ${ }^{19-30}$ with an even smaller number of comparative studies published to date $(20,25,27,29)$. In the present study to the best of our knowledge, we report the first matched case-control study comparing between MIP versus open pancreatectomy (OP) for SPPN.

\section{MATERIALS AND METHODS}

We performed a retrospective electronic chart review of all patients who underwent surgical management for pathologically confirmed SPPN at Singapore General Hospital from 2000 to 2017. Parameters studied included baseline demographic and clinical characteristics, perioperative parameters and long-term follow-up data. This study has been approved by the Institutional Ethics Review Board.

All patients underwent thorough preoperative clinical evaluation and cross-sectional imaging for disease staging and surgical planning. Additional diagnostic evaluations such as endoscopic ultrasound-guided fine needle aspiration cytology were offered and undertaken where clinically indicated by the managing surgeon. Although minimally-invasive pancreatic surgery was first adopted at our institution in 2006, this was only performed sporadically up till 2011 when surgeons in our institution decided to systematically adopt and pursue minimally invasive hepatopancreatobiliary surgery including pancreatectomies. ${ }^{31,32}$

The type of resection (pancreatoduodenectomy, subtotal pancreatectomy or distal pancreatectomy) and operative approach (open or minimally-invasive) were determined based on clinical and tumor characteristics after a thorough discussion between the patient and managing surgeon. In particular, the choice between open and minimally-invasive surgery was frequently based on individual surgeon preference and not by institution protocol

In comparing patients managed via open as opposed to minimally invasive pancreatectomy, we performed a $2: 1$ matching using baseline characteristics likely to affect surgical outcomes and prognosis in patients with SPPN age, gender, tumour size and type of pancreatectomy per- formed. Preoperative fitness for general anesthesia was graded based on the American Society of Anesthesiologists (ASA) score. ${ }^{33}$ Postoperative morbidities were graded using the Clavien-Dindo classification. ${ }^{34}$ Postoperative pancreatic fistulas (POPF) were defined and graded in accordance with the 2016 update of the International Study Group (ISGPS) definition and grading of POPF. ${ }^{35}$ All complications were recorded up to 30 days and during the index hospital stay. Additionally, 90-day/in-hospital mortalities were recorded for all patients.

Statistical analysis was performed using SPSS Statistics Version 19.0 (Armonk NY, IBM Corp). Continuous and categorical variables and survival data were analyzed using the Mann-Whitney U test, chi-square test or Fischer's exact test, and Kaplan-Meier analysis respectively as appropriate, with a statistical significance level of $5 \%$ used.

\section{RESULTS}

There were a total of 40 patients who had a median age of 40.3 years (range 16.5-64.4) and female sex predominance $(n=34,85.0 \%)$ over a median follow-up duration of 67 months. The majority of SPPN in our study were located in the neck, body and/or tail of the pancreas $(\mathrm{n}=29,72.5 \%)$, with a median tumor size of $55 \mathrm{~mm}$ (range 15-155). All cases were localized to the pancreas at initial presentation, with no evidence of distant metastases on preoperative staging. Nine patients underwent MIP including six via laparoscopy, one via laparoscopy-assisted (hybrid) PD with open reconstruction, and two via robotic assistance. There were no cases of open conversions. The overall and major postoperative morbidity rate were $35.0 \%$ and $10.0 \%$ respectively.

\section{Comparison between patients who underwent MIP vs OP}

Prior to matching, there were no significant differences in baseline demographics, perioperative characteristics and postoperative/oncologic outcomes between patients managed via OP and MIP (Tables 1,2). After 2:1 matching based on age, gender and tumor size, we found that MIP for SPPN was associated with a longer median operating time (305 vs 178 minutes, $p=0.046$ ) and shorter median postoperative stay ( 6 vs 9 days, $p=0.035$ ) (Table 2). There were no significant differences in intraoperative blood loss 
Table 1. Comparison between the baseline demographics and perioperative data of patients who underwent open and minimally invasive pancreatectomy

\begin{tabular}{|c|c|c|c|c|c|}
\hline Characteristic & $\begin{array}{l}\text { Min. Invasive } \\
(\mathrm{n}=9)\end{array}$ & $\begin{array}{l}\text { Open (All) } \\
\quad(n=31)\end{array}$ & $p$-value & $\begin{array}{l}\text { Open (Matched) } \\
(\mathrm{n}=18)\end{array}$ & $p$-value \\
\hline Median age (range), years & $36.7(19.4-64.4)$ & $40.3(16.5-60.9)$ & 0.371 & $43.3(16.5-60.9)$ & 0.232 \\
\hline \multicolumn{6}{|l|}{ Ethnicity, $\mathrm{n}(\%)$} \\
\hline Chinese & $7(77.8)$ & $25(80.6)$ & \multirow[t]{4}{*}{0.277} & $14(77.8)$ & \multirow[t]{4}{*}{0.453} \\
\hline Malay & $0(0.0)$ & $1(3.2)$ & & $1(5.6)$ & \\
\hline Indian & $1(11.1)$ & $0(0.0)$ & & $0(0.0)$ & \\
\hline Others & $1(11.1)$ & $5(16.1)$ & & $3(16.7)$ & \\
\hline Female gender, n (\%) & $8(88.9)$ & $26(83.9)$ & 1.000 & $14(77.8)$ & 0.636 \\
\hline Median BMI (range), $\mathrm{kg} / \mathrm{m}^{2}$ & $22.6(19.1-32.3)$ & $21.7(16.0-40.4)$ & 0.199 & $21.7(16.0-29.4)$ & 0.193 \\
\hline Symptoms, n (\%) & $3(33.3)$ & $16(51.6)$ & 0.457 & $11(61.1)$ & 0.236 \\
\hline \multicolumn{6}{|l|}{ ASA score, n (\%) } \\
\hline 1 & $6(66.7)$ & $18(58.1)$ & \multirow[t]{2}{*}{0.717} & $11(61.1)$ & \multirow[t]{2}{*}{1.000} \\
\hline 2 & $3(33.3)$ & $13(41.9)$ & & $7(38.9)$ & \\
\hline Previous abdominal surgery, $\mathrm{n}(\%)$ & $1(11.1)$ & $4(12.9)$ & 1.000 & $3(16.7)$ & 1.000 \\
\hline Median tumour size (range), $\mathrm{mm}$ & $35(25-125)$ & $70(15-155)$ & 0.069 & $58(15-140)$ & 0.433 \\
\hline \multicolumn{6}{|l|}{ Tumour location, $\mathrm{n}(\%)$} \\
\hline Head/uncinate & $1(11.1)$ & $10(32.3)$ & \multirow[t]{2}{*}{0.399} & $3(16.7)$ & \multirow[t]{2}{*}{1.000} \\
\hline Neck/body/tail & $8(88.9)$ & $21(67.7)$ & & $15(83.3)$ & \\
\hline \multicolumn{6}{|l|}{ Pancreatectomy, n (\%) } \\
\hline Pancreatoduodenectomy & $1(11.1)$ & $9(29.0)$ & \multirow[t]{2}{*}{0.404} & $2(11.1)$ & \multirow[t]{2}{*}{1.000} \\
\hline Subtotal/distal pancreatectomy & $8(88.9)$ & $22(71.0)$ & & $16(88.9)$ & \\
\hline
\end{tabular}

Table 2. Comparison between the perioperative and oncologic outcomes of patients who underwent open and minimally invasive pancreatectomy

\begin{tabular}{|c|c|c|c|c|c|}
\hline Characteristic & $\begin{array}{l}\text { Min. Invasive } \\
(\mathrm{n}=9)\end{array}$ & $\begin{array}{l}\text { Open (All) } \\
(\mathrm{n}=31)\end{array}$ & $p$-value & $\begin{array}{c}\text { Open (Matched) } \\
(\mathrm{n}=18)\end{array}$ & $p$-value \\
\hline Median operating time (range), min & $305(140-560)$ & $188(110-520)$ & 0.093 & $178(110-390)$ & 0.046 \\
\hline Median blood loss (range), $\mathrm{ml}$ & $200(50-600)$ & $201(0-1500)$ & 0.838 & $150(0-1000)$ & 0.815 \\
\hline Intraoperative blood transfusion, $\mathrm{n}(\%)$ & $1(11.1)$ & $9(30.0)$ & 0.400 & $5(27.8)$ & 0.628 \\
\hline Postoperative morbidity, n (\%) & $3(33.3)$ & $11(35.5)$ & 1.000 & $8(44.4)$ & 0.692 \\
\hline Major morbidity (Clavien-Dindo grade >2), n (\%) & $1(11.1)$ & $3(9.7)$ & 1.000 & $2(11.1)$ & 1.000 \\
\hline Postoperative pancreatic fistula, n (\%) & $1(11.1)$ & $3(9.7)$ & 1.000 & $2(11.1)$ & 1.000 \\
\hline \multicolumn{6}{|l|}{ Pancreatic fistula grade, $\mathrm{n}(\%)$} \\
\hline Grade B & $1(11.1)$ & $2(6.5)$ & 0.781 & $2(11.1)$ & 1.000 \\
\hline Grade C & $0(0.0)$ & $1(3.2)$ & & $0(0.0)$ & \\
\hline Reoperation, n (\%) & $0(0.0)$ & $2(6.5)$ & 1.000 & $1(5.6)$ & 1.000 \\
\hline 90-day/in-hospital mortality, n (\%) & $0(0.0)$ & $1(3.2)$ & 1.000 & $0(0.0)$ & 1.000 \\
\hline Median postoperative stay (range), days & $6(4-14)$ & $8(4-26)$ & 0.051 & $9(4-26)$ & 0.035 \\
\hline Readmission, n (\%) & $1(11.1)$ & $3(9.7)$ & 1.000 & $3(16.7)$ & 1.000 \\
\hline Median closest resection margin (range), $\mathrm{mm}$ & $2(1-8)$ & $1(1-15)$ & 0.907 & $2(1-15)$ & 0.770 \\
\hline Median lymph node yield (range) & $1(0-18)$ & $4(0-24)$ & 0.483 & $2(0-24)$ & 0.860 \\
\hline 5 -year overall survival (\%) & 100.0 & 96.6 & 0.577 & 100.0 & 1.000 \\
\hline 5-year disease-free survival $(\%)$ & 100.0 & 92.0 & 0.432 & 91.7 & 0.457 \\
\hline
\end{tabular}

and blood transfusion requirements, postoperative morbidity (including postoperative pancreatic fistula) and mortality, resection margins and lymph node yield (Table 2).

The 5-year overall and disease-free survival in our cohort was $97.4 \%$ and $96.2 \%$ respectively. There were two patients with tumor recurrences at 36 (local, nodal and hepatic recurrences) and 77 (nodal recurrence) months following open distal pancreatectomy. There was no significant difference in overall and disease-free survival between patients managed via OP and MIP (Table 2). 


\section{DISCUSSION}

In the present study, the majority of our patients were young healthy females with tumors located in the neck, body and/or tail of the pancreas, which is consistent with the demographic features of the typical SPPN patient reported in existing literature. ${ }^{1-3,7}$ Additionally, we also found excellent long-term prognosis after complete surgical resection for SPPN with 5-yr OS rates of 96\%. ${ }^{2,7,9,11,36}$ Hence, in addition to improving short-term perioperative outcomes with the performance of MIS in this group of patients, ${ }^{19-30}$ further potential longer-term benefits associated with MIS such as improved wound cosmesis, decreased long-term wound complications such as paresthesia and chronic pain and decreased intra-abdominal adhesions could be especially important.

One of the first series of laparoscopic distal pancreatectomies for SPPN comprising 10 patients was published by Cavallini et al. ${ }^{30}$ in 2011, which reported 40\%, 20\% and $0 \%$ postoperative morbidity, reoperation and perioperative mortality rates respectively. Since then, several institutions have published their experience with MIP for SPPN, all of which have consistently concluded that MIP is a safe and feasible approach in the management of SPPN. . $^{19,21-24,26,28}$ These studies however lack comparative analysis against SPPN managed via a conventional open approach.

In our comparative study, we found an overall and major postoperative morbidity rate of $35.0 \%$ and $10.0 \%$ respectively, which was similar to that reported previously.,11,37 Our findings demonstrate comparable short-term perioperative outcomes between open and MIP for SPPN, including intraoperative blood loss and transfusion requirements, postoperative morbidity and mortality rates, as well as reoperation and readmission rates. In addition, oncological safety in terms of resection margins and lymph node yield was also comparable. The benefit of a shorter postoperative length of stay associated with MIP came with the tradeoff of a longer median operating time in our study.

To date, only date only 4 comparative studies have been published on MIP vs open surgery for SPPN. These studies are summarized in Table 3 . The first comparative study of minimally-invasive versus open distal pancreatectomy for SPPN by Kang et al. ${ }^{29}$ in 2011 compared 24 open and 11 MIP and found that MIP was associated with earlier oral intake and a shorter hospital stay without any

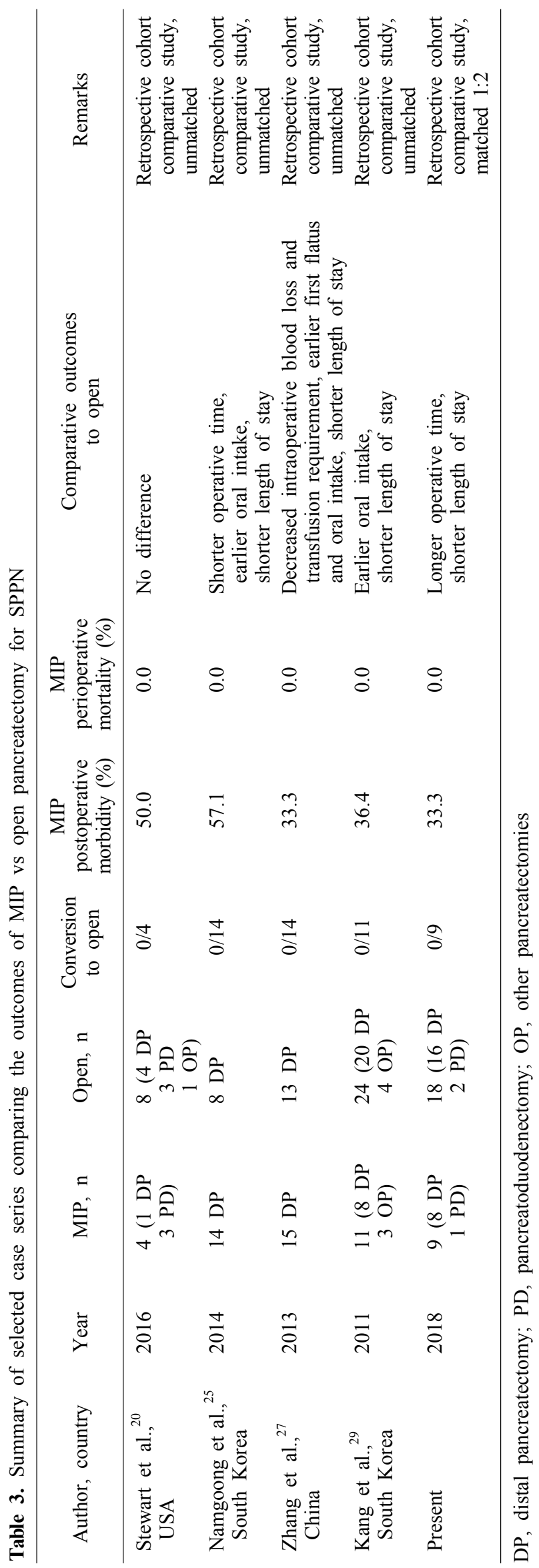


significant difference in postoperative morbidity. Notably however, the median tumor size was significantly smaller in the MIP group, which potentially confounded their findings. A subsequent retrospective cohort study by Zhang et al. ${ }^{27}$ in 2013 comparing 13 open and 15 laparoscopic distal pancreatectomies for SPPN reported findings of comparable postoperative outcomes, shorter postoperative length of stay and comparable oncological clearance, similar to our study. Zhang et al. ${ }^{27}$ however found no difference in operating time, and reported additional benefits of a shorter time to first flatus and starting diet. Of note as well, there was a trend towards a smaller tumor size in the laparoscopic group (5.1 vs $7.7 \mathrm{~cm}, p=0.05$ ) which may have in part accounted for the benefits conferred by a laparoscopic approach.

A retrospective pediatric cohort study by Namgoong et al. $^{25}$ in 2014 comparing 8 open and 14 laparoscopic distal pancreatectomies for patients under 18 years of age reported a shorter operative time, earlier commencement of oral intake and shorter hospitalization in the laparoscopic group. Further highlighting the prevalence of selection bias in retrospective analyses of open versus laparoscopic management of SPPN, this study also had a significantly smaller median tumor size (4.5 vs $10.7 \mathrm{~cm}, p=0.024)$ in the laparoscopic group. The most recent comparative study by Stewart et al. ${ }^{20}$ in 2016 comparing 8 open and 4 laparoscopic pancreatectomies reported - within the limitations of its small sample size - no difference in postoperative length of stay, and a trend towards lower postoperative morbidity rate in the laparoscopic group $(50.0 \%$ vs $62.5 \%$, $p=0.28$ ).

We recognize the inherent limitations of our study as a single-institution retrospective review with a small sample size, largely owing to the fact that SPPN remains a rare condition. However, to the best of our knowledge, while our study represents the fifth comparative study examining open versus MIP for SPPN, it has the largest (pre-matching) study sample of all comparative studies to date, and is the first to perform a matched comparison to mitigate potential selection bias.

In conclusion, MIP is a safe and viable option in the management of SPPN with the benefit of a shorter postoperative length of stay at the expense of a longer operation time. Further studies with long-term follow-up are needed in larger patient cohorts to corroborate these find- ings and to determine if there are other potential longer-term benefits such as improved cosmesis and decreased long-term wound complications.

\section{REFERENCES}

1. Yu PF, Hu ZH, Wang XB, Guo JM, Cheng XD, Zhang YL, et al. Solid pseudopapillary tumor of the pancreas: a review of 553 cases in Chinese literature. World J Gastroenterol 2010;16:120914.

2. Goh BK, Tan YM, Cheow PC, Chung AY, Chow PK, Wong WK, et al. Solid pseudopapillary neoplasms of the pancreas: an updated experience. J Surg Oncol 2007;95:640-644.

3. Lima CA, Silva A, Alves C, Alves A Jr, Lima S, Cardoso E, et al. Solid pseudopapillary tumor of the pancreas: clinical features, diagnosis and treatment. Rev Assoc Med Bras (1992) 2017;63:219-223.

4. Frantz VK. Tumors of the pancreas. Washington: Armed Forces Institute of Pathology, 1959:32-33.

5. Hamoudi AB, Misugi K, Grosfeld JL, Reiner CB. Papillary epithelial neoplasm of pancreas in a child. Report of a case with electron microscopy. Cancer 1970;26:1126-1134.

6. Kloppel G, Solcia E, Longnecker DS, Capella C, Sobin LH. Histological typing of tumours of the exocrine pancreas. Berlin: Springer-Verlag, 1996:120-128.

7. Law JK, Ahmed A, Singh VK, Akshintala VS, Olson MT, Raman SP, et al. A systematic review of solid-pseudopapillary neoplasms: are these rare lesions? Pancreas 2014;43:331-337.

8. Antoniou EA, Damaskos C, Garmpis N, Salakos C, Margonis GA, Kontzoglou K, et al. Solid pseudopapillary tumor of the pancreas: a single-center experience and review of the literature. In Vivo 2017;31:501-510.

9. Song H, Dong M, Zhou J, Sheng W, Zhong B, Gao W. Solid pseudopapillary neoplasm of the pancreas: clinicopathologic feature, risk factors of malignancy, and survival analysis of 53 cases from a single center. Biomed Res Int 2017;2017:5465261.

10. de Castro SM, Singhal D, Aronson DC, Busch OR, van Gulik TM, Obertop H, et al. Management of solid-pseudopapillary neoplasms of the pancreas: a comparison with standard pancreatic neoplasms. World J Surg 2007;31:1130-1135.

11. Reddy S, Cameron JL, Scudiere J, Hruban RH, Fishman EK, Ahuja N, et al. Surgical management of solid-pseudopapillary neoplasms of the pancreas (Franz or Hamoudi tumors): a large single-institutional series. J Am Coll Surg 2009;208:950-957; discussion 957-959.

12. Tang LH, Aydin H, Brennan MF, Klimstra DS. Clinically aggressive solid pseudopapillary tumors of the pancreas: a report of two cases with components of undifferentiated carcinoma and a comparative clinicopathologic analysis of 34 conventional cases. Am J Surg Pathol 2005;29:512-519.

13. Yi X, Chen S, Wang W, Zou L, Diao D, Zheng Y, et al. A systematic review and meta-analysis of laparoscopic and open distal pancreatectomy of nonductal adenocarcinomatous pancreatic tumor (NDACPT) in the pancreatic body and tail. Surg Laparosc Endosc Percutan Tech 2017;27:206-219.

14. Nakamura M, Nakashima H. Laparoscopic distal pancreatectomy and pancreatoduodenectomy: is it worthwhile? A meta-analysis of laparoscopic pancreatectomy. J Hepatobiliary Pancreat Sci 2013; 20:421-428.

15. Venkat R, Edil BH, Schulick RD, Lidor AO, Makary MA, Wolfgang CL. Laparoscopic distal pancreatectomy is associated with significantly less overall morbidity compared to the open 
technique: a systematic review and meta-analysis. Ann Surg 2012;255:1048-1059.

16. Sui CJ, Li B, Yang JM, Wang SJ, Zhou YM. Laparoscopic versus open distal pancreatectomy: a meta-analysis. Asian J Surg 2012;35:1-8.

17. Riviere D, Gurusamy KS, Kooby DA, Vollmer CM, Besselink MG, Davidson BR, et al. Laparoscopic versus open distal pancreatectomy for pancreatic cancer. Cochrane Database Syst Rev 2016;4:CD011391.

18. Kooby DA, Hawkins WG, Schmidt CM, Weber SM, Bentrem DJ, Gillespie TW, et al. A multicenter analysis of distal pancreatectomy for adenocarcinoma: is laparoscopic resection appropriate? J Am Coll Surg 2010;210:779-785, 786-787.

19. Senthilnathan P, Dhaker KC, Kaje V, Naidu SB, Sarvani M, Sabnis SC, et al. Laparoscopic management of solid pseudo papillary neoplasm of pancreas in tertiary care center from south India. Pancreatology 2017;17:927-930.

20. Stewart CL, Meguid C, Chapman B, Schulick R, Edil BH. Evolving trends towards minimally invasive surgery for solid-pseudopapillary neoplasms. Ann Surg Oncol 2016;23:4165-4168.

21. Nakamura Y, Matsushita A, Katsuno A, Yamahatsu K, Sumiyoshi $\mathrm{H}$, Mizuguchi Y, et al. Clinical outcomes for 14 consecutive patients with solid pseudopapillary neoplasms who underwent laparoscopic distal pancreatectomy. Asian J Endosc Surg 2016;9:3236.

22. Namur GN, Ribeiro TC, Souto MM, Figueira ER, Bacchella T, Jureidini R. Minimally invasive surgery for pseudopapillary neoplasm of the pancreas. Arq Bras Cir Dig 2016;29:97-101.

23. Cai Y, Peng B, Mai G, Ke N, Liu X. Laparoscopic distal pancreatectomy for solid-pseudopapillary tumor of the pancreas. Surg Laparosc Endosc Percutan Tech 2015;25:e8-e10.

24. Afridi SA, Kazaryan AM, Marangos IP, Røsok BI, Fretland ÅA, Yaqub S, et al. Laparoscopic surgery for solid pseudopapillary tumor of the pancreas. JSLS 2014;18:236-242.

25. Namgoong JM, Kim DY, Kim SC, Kim SC, Hwang JH, Song KB. Laparoscopic distal pancreatectomy to treat solid pseudopapillary tumors in children: transition from open to laparoscopic approaches in suitable cases. Pediatr Surg Int 2014;30:259-266.

26. Chen XM, Zhang Y, Sun DL. Laparoscopic central pancreatectomy for solid pseudopapillary tumors of the pancreas: our experience with ten cases. World J Surg Oncol 2014;12:312.
27. Zhang RC, Yan JF, Xu XW, Chen K, Ajoodhea H, Mou YP. Laparoscopic vs open distal pancreatectomy for solid pseudopapillary tumor of the pancreas. World J Gastroenterol 2013;19: 6272-6277.

28. Jarry J, Bodin R, Peycru T, Nunez M, Collet D, Cunha AS. Role of laparoscopic distal pancreatectomy for solid pseudopapillary tumor. JSLS 2012;16:552-558.

29. Kang CM, Choi SH, Hwang HK, Lee WJ, Chi HS. Minimally invasive (laparoscopic and robot-assisted) approach for solid pseudopapillary tumor of the distal pancreas: a single-center experience. J Hepatobiliary Pancreat Sci 2011;18:87-93.

30. Cavallini A, Butturini G, Daskalaki D, Salvia R, Melotti G, Piccoli $\mathrm{M}$, et al. Laparoscopic pancreatectomy for solid pseudo-papillary tumors of the pancreas is a suitable technique; our experience with long-term follow-up and review of the literature. Ann Surg Oncol 2011;18:352-357.

31. Goh BKP, Lee SY, Teo JY, Kam JH, Jeyaraj PR, Cheow PC, et al. Changing trends and outcomes associated with the adoption of minimally invasive hepatectomy: a contemporary single-institution experience with 400 consecutive resections. Surg Endosc 2018;32:4658-4665

32. Goh BKP, Lee SY, Kam JH, Soh HL, Cheow PC, Chow PKH, et al. Evolution of minimally invasive distal pancreatectomies at a single institution. J Minim Access Surg 2018;14:140-145.

33. Dripps RD. New classification of physical status. Anethesiology $1963 ; 24: 111$.

34. Dindo D, Demartines N, Clavien PA. Classification of surgical complications: a new proposal with evaluation in a cohort of 6336 patients and results of a survey. Ann Surg 2004;240:205213.

35. Bassi C, Marchegiani G, Dervenis C, Sarr M, Abu Hilal M, Adham M, et al.; International Study Group on Pancreatic Surgery (ISGPS). The 2016 update of the International Study Group (ISGPS) definition and grading of postoperative pancreatic fistula: 11 years after. Surgery 2017;161:584-591.

36. Papavramidis T, Papavramidis S. Solid pseudopapillary tumors of the pancreas: review of 718 patients reported in English literature. J Am Coll Surg 2005;200:965-972.

37. Li G, Baek NH, Yoo K, Hwang JC, Kim JH, Yoo BM, et al. Surgical outcomes for solid pseudopapillary neoplasm of the pancreas. Hepatogastroenterology 2014;61:1780-1784. 